\title{
Axillary lymph nodes and breast cancer metastasis.
}

\author{
1. MBBS, FCPS \\ Associate Professor Anatomy \\ Chandka Medical College \\ Shaheed Mohtarma Benazir Bhutto \\ Medical University Larkana. \\ 2. MBBS, MS \\ Assistant Professor Surgery \\ Chandka Medical College \\ Shaheed Mohtarma Benazir \\ Bhutto Medical University Larkana. \\ 3. MBBS, FCPS \\ Assistant Professor Surgery \\ Chandka Medical College \\ Shaheed Mohtarma Benazir \\ Bhutto Medical University Larkana. \\ 4. MBBS, FCPS \\ Associate Professor Anatomy \\ Liaquat National Hospital \& \\ Medical College Karachi. \\ 5. MBBS, FCPS \\ Professor Gynae \& Obs \\ Chandka Medical College \\ Shaheed Mohtarma Benazir \\ Bhutto Medical University Larkana. \\ 6. MBBS, FCPS \\ Assistant Professor Surgery \\ Chandka Medical College \\ Shaheed Mohtarma Benazir \\ Bhutto Medical University Larkana.
}

Correspondence Address:

Dr. Shahid Hussain Soomro

Banglo No. 16, Type 3, Staff Colony,

Chandka Medical College, Larkana

husainshahid79@yahoo.com

Article received on:

06/08/2020

Accepted for publication:

06/10/2020
Shahid Hussain Soomro', Abdul Sattar Abro², Vaqar-e-Sahar Shah ${ }^{3}$, Saima Ather Shaikh", Shabnum Naz Shaikh ${ }^{5}$, Ehsanullah Malik ${ }^{6}$

ABSTRACT ... Objectives: The purpose of current study is to evaluate the correlation of axillary lymph node status with metastases in patients presented with carcinoma breast. Study Design: Prospective study. Setting: Surgical Unit 1, CMC Hospital Larkana. Period: March 2019 to January 2020. Material \& Methods: Female patients presented with carcinoma breast were assessed clinically and by investigation then underwent a mastectomy and axillary dissection (sampling or clearance). Data was entered into pre-designed proforma. After proper staging, surgery was done in all patients accordingly. Lymph node involvement was confirmed histopathology. Then it was correlated with clinical findings. Results: Fifty-five female patients of proven carcinoma breast underwent a mastectomy and axillary dissection. The majority of the patients $(76 \%)$ were between $30-60$ years, the median age being 45 years. The left breast contained the tumor in $30(55.5 \%)$ patients while the rest of the patients had the right breast involved. The size of the tumor varied from $2 \mathrm{~cm}$ to $12 \mathrm{~cm}$. $33(61 \%)$ patients were in the premenopausal state while 21 (38.88\%) were in postmenopausal state. In 07 patients (13\%) the axillary lymph nodes were not palpable while in the rest of the 47 patients $(87 \%)$, the axillary lymph nodes were palpable to a variable extent. Most of the patients were in an advanced stages. Among seven patients (N0), histopathology revealed positive lymph nodes in 3/7 (42.85\%) patients. Conclusion: Breast carcinoma is a serious type of carcinoma affecting the younger generation in our community, usually diagnosed at a late stage. Clinical examination is not an effective way for proper staging. Further investigations should be performed for accurate staging and management.

Key words: $\quad$ Axillary Lymph Nodes, Breast Cancer, Clinical Examination, Metastasis.

Article Citation: Soomro SH, Abro AS, Shah Vaqar-e-Sahar, Shaikh SA, Shaikh SN, Malik E. Axillary lymph nodes and breast cancer metastasis. Professional Med J 2021; 28(7):978-982. https://doi.org/10.29309/TPMJ/2021.28.07.5919

\section{INTRODUCTION}

Breast carcinoma is the most common malignancy in females throughout world and makes $2^{\text {nd }}$ leading cause of death among cancer patients. ${ }^{1,2}$ In Pakistani population it has been observed at young age contrary to the Western countries where it is more frequent in old aged females (after 60 years). ${ }^{3}$ Patients with breast cancer in developing countries, including Pakistan, present in advanced stage and lead to high percentage of mortality.

There are various risk factors for the development of breast carcinoma including advanced age, early start of menstrual cycle, delayed menopause, increased age at first pregnancy, no parity, obesity, and prolonged use of oral contraceptive pills.
Mutation of some genes like BRCA1 and BRCA 2 may cause carcinoma infemales at earlier age. ${ }^{4}$

The American joint committee on cancer used Tumor-Node-Metastasis system (TNM) for staging purpose. This staging system depends upon the size, and extent of the primary tumor, regional lymph nodes involvement, and distant spread. ${ }^{5}$ The prognosis of breast carcinoma depends upon the stage of disease at the time of diagnosis. Treated at early stage is cost effective with excellent outcome while treating advancedstage disease is expensive with poor outcome.

Axillary nodal involvement is considered as the most critical factor in the prognosis of breast carcinoma. It helps in the treatment choose for 
individual patient. ${ }^{6}$ If axillary lymph nodes are not palpable on clinical examination it should not be considered as negative until excluded by other investigations. Sentinel lymph node biopsy has become the gold standard for axillary lymph node staging in breast cancer patients ${ }^{7}$ it is now well known that axillary lymph node status can be assessed accurately with sentinel lymph node biopsy. ${ }^{8}$ After proper assessment through investigations the treatment plan should be made.

The treatment of breast carcinoma depends upon the stage of disease. Surgery is main treatment strategy, which may be combined with chemo or radiotherapy given as neoadjuvant or as adjuvant therapy. The surgical options may include breast conservation surgery with sentinel lymph node biopsy or the modified radical mastectomy and axillary lymph nodes dissection. Hormonal therapy may be needed in some patients. Early intervention can reduce the mortality by $30 \%$.

The aim of this study was to assess the accuracy of clinical staging of patients presented with breast carcinoma in our setup specially those present in early stage of disease.

\section{MATERIAL \& METHODS}

This study was conducted at Department of Surgery, teaching hospital of Chandka Medical College Shaheed Mohtarma Benazir Bhutto Medical University Larkana, Pakistan from March 2019 to January 2020. Fifty four patients diagnosed as breast carcinoma on histopathology were selected for study by non- probability purposive technique and patients who did not give consent were excluded from study.

Biodata including age of patient, menopausal status, parity, breast feeding, affected side, stage of disease and histopathological findings were also noted on designed proforma. The data analysis was done by SPSS $v 20$. Mean \pm SD was calculated for age of the patient. Frequency and percentage were calculated for above mentioned parameters.

\section{RESULTS}

Fifty four female patients undergoing mastectomy and axillary dissection were studies. Majority of patients 42 (77\%) were between 30-60 years, median age patients was $45+/-4.35$ years. Five $(9.2 \%)$ patients were unmarried. Forty one (46\%) patients had history of breast feeding to their children. Seven (13\%) had family history of breast cancer.

Left breast contained the tumor in 30 (55\%) patients while the rest of patients had right breast involved. 33 (61.11\%) patients were in pre-menopausal state and 21 (38.88\%) were in postmenopausal state (Figure-1).

In 07 patients (13\%) the axillary lymph nodes were not palpable while in rest of the 47 patients (87\%), the axillary lymph nodes were palpable to variable extent (Table-I). Among these 7 patients in whom clinically lymph nodes were not palpable, metastasis to lymph nodes was confirmed in 3/7 (42.85\%) patients on histopathology (Figure-2).

\section{Menstrual status}

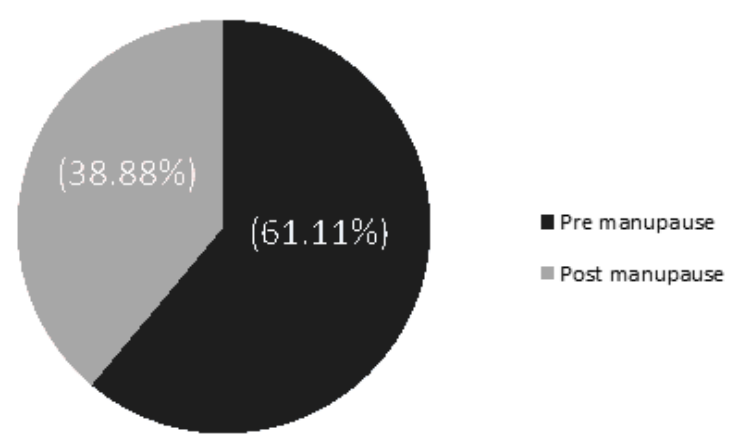

Figure-1. Graph showing the menstrual status of patients presented with breast carcinoma.

\begin{tabular}{|c|l|c|c|}
\hline & \multicolumn{1}{|c|}{ Lymph node status } & No of Patients \\
\hline 1. & Axillary lymph nodes not palpable(No) & 07 & 13 \\
\hline 2. & Freely mobile axillary lymph nodes (N1) & 14 & 26 \\
\hline 3. & Matted axillary lymph nodes without fixity to surrounding structures(N2) & 18 & 33.33 \\
\hline 4. & Lymph nodes fixed to deeper structures (N3) & 14 & 26 \\
\hline
\end{tabular}




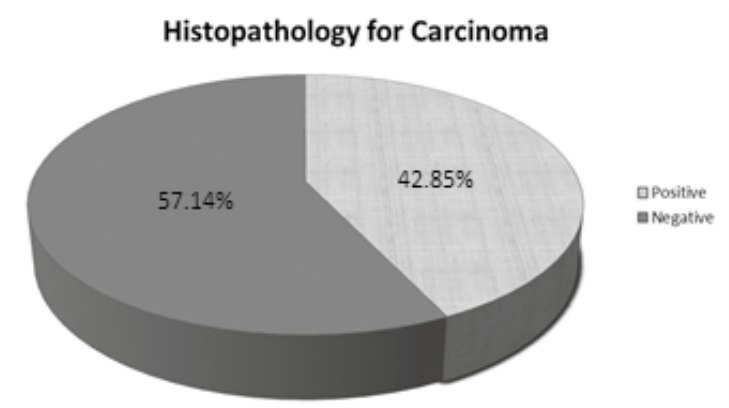

Figure-2. Percentage of axillary lymph node positive patients who presented with NO.

\section{DISCUSSION}

Breast carcinoma comprises $23 \%$ of all cancers in women throughout the globe. ${ }^{9}$ The incidence is rising in developing countries. ${ }^{10}$ Proper management of breast cancer depends upon its proper diagnosis and staging. Sentinel lymph node biopsy (SLNB) has evolved significantly the management of breast cancer ${ }^{11}$ (Giuliano, 2016 \#364). Axillary Lymph node involvement is considered as an important prognostic factor in breast carcinoma. Loco-regional progression of the disease effect on the recurrence of disease and patient's survival. ${ }^{8}$ The relation between lymph node metastasis and survival has been demonstrated ${ }^{12,13}$ and it reduces the survival rates are up to $40 \%$ in node-positive patients when compared with those who are node-negative ${ }^{12}$ therefore it's important to stage the patient pre operatively and assess the nodal status. ${ }^{14,15}$ Status of axillary lymph nodes keeps important impact on therapy decision making i.e. surgical, chemotherapy radiological or combined. ${ }^{16,17}$

In our study mean age of patients was 45 years. Shukla A et al in their study have also mentioned the mean age of patients $51.18 \pm 11.93$ years. ${ }^{18}$ This indicates earlier involvement of breast cancer in our population. Sharif MA et al in their study have mentioned that Majority (62\%) patients with breast cancer were under 50 years as against the Western epidemiology. ${ }^{19}$ In our earlier study we had found same finding that breast carcinoma is going to involve younger population in our society. ${ }^{20}$
In our study $55 \%$ patients were having left side involvement. Shukla A also showed that majority $(62 \%)$ cases of breast carcinoma involving the left side. but this does not have any influence on metastasis. ${ }^{18}$

Like age, menopausal status has great influence breast carcinoma. ${ }^{19} 61.11 \%$ of patients were in pre-menopausal state. A large meta-analysis has described the strong correlation between menstrual cycle status and increased risk of breast carcinoma, specially starting and cessation age is very important. There is a $5 \%$ increased risk of breast cancer with each year earlier start of menstrual cycle. ${ }^{21}$ Studies conducted in women at menopause stage revealed increased risk of breast carcinoma risk in those who had experienced prolonged reproductive period $(>490$ menstrual cycles) in comparison to women with fewer or irregular cycles. ${ }^{22}$ This indicates that fluctuations in ovarian hormones associated with menstrual cycling enhance the susceptibility of breast cancer. ${ }^{23}$ Increased level of estrogen and progesterone during main proliferative phase and mid secretory phase enhance the development of mammary glands epithelia, which may contribute in the development of breast carcinoma. ${ }^{24,25}$

In our study $7(13 \%)$ patients were clinically negative for lymph nodes involvement but 3 among them become positive for metastasis on histopathology thus making the $42.85 \%$ false negative diagnosis on clinical assessment. Somashekhar et al in their study mentioned the $3.7 \%$ false negative result. ${ }^{7}$ Seok et al in their study assessed 104 patients of breast cancer who were clinically negative for axillary lymph node metastasis. After performing ultrasonography, FDG, PET, and MRI, they found that 21(20.2\%) patients of them were having axillary lymph node metastases(26). Clinical examination is biased and varies from person to person. There are more chances of false negativity, thus other sophisticated investigation should be carried out for proper staging of breast cancer. SLNB using methylene blue dye and radio-active Tc99m sulphur colloid has high accuracy in axilla staging with low rate of false negativity in early breast 
cancer patients. ${ }^{7}$ Liu $\mathrm{M}$ et al. have suggested that while treating patients with clinically node negative should be assessed by ultrasound and sentinel lymph node biopsy. ${ }^{27}$

\section{CONCLUSION}

Although clinical examination of axilla in patients with breast cancer is of utmost importance and it helps in having an idea of nodal metastases, but keeping in view the false negatives, other tests and techniques need to be applied before deciding any treatment plan and to avoid unnecessary surgery and recurrence.

\section{Copyright (}

\section{REFERENCES}

1. Mohammed AA. Predictive factors affecting axillary lymph node involvement in patients with breast cancer in Duhok: Cross-sectional study. Annals of medicine and surgery (2012). 2019; 44:87-90.

2. Al-Gburi ASA, Alwan NAS. Correlation between breast self-examination practices and demographic characteristics, risk factors and clinical stage of breast cancer among Iraqi patients. Open access Macedonian journal of medical sciences. 2019; 7(19):3216-20.

3. Naeem M, Nasir A, Aman Z, Ahmad T, Samad A. Frequency of HER-2/neu receptor positivity and its association with other features of breast cancer. Journal of Ayub Medical College, Abbottabad: JAMC. 2008; 20(3):23-6.

4. Coletta AM, Peterson SK, Gatus LA, Krause KJ, Schembre SM, Gilchrist SC, et al. Diet, weight management, physical activity and ovarian \& breast cancer risk in women with BRCA1/2 pathogenic Germline gene variants: systematic review. 2020; 18:5.

5. Edge SB, Compton CC. The American Joint Committee on Cancer: The 7th edition of the AJCC cancer staging manual and the future of TNM. Annals of surgical oncology. 2010; 17(6):1471-4.

6. Peintinger F, Reitsamer R, Smidt ML, Kuhn T, Liedtke C. Lymph nodes in breast cancer - What can we learn from translational research? Breast care (Basel, Switzerland). 2018; 13(5):342-7.

7. Somashekhar SP, Zaveri Shabber S, Udupa Venkatesh K, Venkatachala K, Parameshwaran, Vasan Thirumalai MM. Sentinel lymphnode biopsy in early breast cancer using methylene blue dye and radioactive sulphur colloid - a single institution Indian experience. The Indian journal of surgery. 2008; 70(3):111-9.
8. Giuliano AE, Ballman K, McCall L, Beitsch P, Whitworth PW, Blumencranz $P$, et al. Locoregional recurrence after sentinel lymph node dissection with or without axillary dissection in patients with sentinel lymph node metastases: long-term follow-up from the American college of surgeons oncology group (Alliance) ACOSOG Z0011 Randomized Trial. Annals of surgery. 2016; 264(3):413-20.

9. Nottegar A, Veronese N, Senthil M, Roumen RM, Stubbs $B$, Choi $A H$, et al. Extra-nodal extension of sentinel lymph node metastasis is a marker of poor prognosis in breast cancer patients: A systematic review and an exploratory meta-analysis. European journal of surgical oncology: The journal of the European Society of Surgical Oncology and the British Association of Surgical Oncology. 2016; 42(7):919-25.

10. Tonellotto F, Bergmann A. Impact of number of positive lymph nodes and lymph node ratio on survival of women with node-positive breast cancer. 2019; 15(2):76-84.

11. Giuliano AE, Hunt KK, Ballman KV, Beitsch PD, Whitworth PW, Blumencranz PW, et al. Axillary dissection vs no axillary dissection in women with invasive breast cancer and sentinel node metastasis: A randomized clinical trial. Jama. 2011; 305(6):569-75.

12. Danko ME, Bennett KM, Zhai J, Marks JR, Olson JA, Jr. Improved staging in node-positive breast cancer patients using lymph node ratio: results in 1,788 patients with long-term follow-up. Journal of the American College of Surgeons. 2010; 210(5):797-805. e1, -7 .

13. Neri A, Marrelli D, Roviello F, De Stefano A, Guarnieri A, Pallucca $E$, et al. Prognostic value of extracapsular extension of axillary lymph node metastases in $\mathrm{T} 1$ to T3 breast cancer. Annals of surgical oncology. 2005; 12(3):246-53.

14. Fernández AG, Fraile $M$, Giménez N, Reñe A, Torras $M$, Canales $L$, et al. Use of axillary ultrasound, ultrasound-fine needle aspiration biopsy and magnetic resonance imaging in the preoperative triage of breast cancer patients considered for sentinel node biopsy. Ultrasound in medicine \& biology. 2011; 37(1):16-22.

15. Koelliker SL, Chung MA, Mainiero MB, Steinhoff MM, Cady B. Axillary lymph nodes: US-guided fineneedle aspiration for initial staging of breast cancercorrelation with primary tumor size. Radiology. 2008; 246(1):81-9. 
16. Martin FT, O'Fearraigh C, Hanley C, Curran C, Sweeney $\mathrm{KJ}$, Kerin MJ. The prognostic significance of nodal ratio on breast cancer recurrence and its potential for incorporation in a new prognostic index. The breast journal. 2013; 19(4):388-93.

17. Vinh-Hung V, Nguyen NP, Cserni G, Truong P, Woodward W, Verkooijen HM, et al. Prognostic value of nodal ratios in node-positive breast cancer: A compiled update. Future oncology (London, England). 2009; 5(10):1585-603.

18. Shukla A, Jain S, Swarnkar M. Correlation of axillary lymph nodes involvement and Nottingham prognostic index with various histopathologic prognostic factors in invasive breast carcinoma. International Surgery Journal. 2019; 6(4):1187-93.

19. Sharif MA, Mamoon N, Mushtaq S, Khadim MT. Age related association of $\mathrm{Her-2/neu}$ with prognostic markers in female breast carcinoma. Journal of the College of Physicians and Surgeons-Pakistan: JCPSP. 2010; 20(9):590-4.

20. Soomro SH, Abro AA, Soomro H, Abro $H$, Bhatti $N$. Causes of delayed presentation of breast carcinoma in our society. Rawal Medical Journal. 2012; 37(3):2969.

21. Cancer CGoHFiB. Menarche, menopause, and breast cancer risk: individual participant meta-analysis, including 118964 women with breast cancer from 117 epidemiological studies. The lancet oncology. 2012; 13(11):1141-51.
22. Chavez-MacGregor M, Elias SG, Onland-Moret NC, van der Schouw YT, Van Gils $\mathrm{CH}$, Monninkhof E, et al. Postmenopausal breast cancer risk and cumulative number of menstrual cycles. Cancer Epidemiology and Prevention Biomarkers. 2005; 14(4):799-804.

23. Atashgaran V, Wrin J, Barry SC, Dasari P, Ingman WV. Dissecting the biology of menstrual cycle-associated breast cancer risk. Frontiers in oncology. 2016; 6:267.

24. Ramakrishnan R, Khan SA, Badve S. Morphological changes in breast tissue with menstrual cycle. Modern pathology. 2002; 15(12):1348-56.

25. Söderqvist G, Isaksson E, von Schoultz B, Carlström K, Tani E, Skoog L. Proliferation of breast epithelial cells in healthy women during the menstrual cycle. American journal of obstetrics and gynecology. 1997; 176(1):123-8.

26. Seok JW, Kim Y, An Y-S, Kim BS. The clinical value of tumor FDG uptake for predicting axillary lymph node metastasis in breast cancer with clinically negative axillary lymph nodes. Annals of nuclear medicine. 2013; 27(6):546-53.

27. Liu M, Yang Y, Xie F, Guo J, Wang S, Yang H, et al. Could axillary clearance be avoided in clinically nodenegative breast cancer patients with positive nodes diagnosed by ultrasound guided biopsy in the postACOSOG Z0011 era? 2019; 14(1):e0210437.

\begin{tabular}{|c|c|c|c|}
\hline \multicolumn{4}{|c|}{ AUTHORSHIP AND CONTRIBUTION DECLARATION } \\
\hline Sr. \# & Author(s) Full Name & Contribution to the paper & Author(s) Signature \\
\hline 1 & Shahid Hussain Soomro & 1st Author & \\
\hline 2 & Abdul Sattar Abro & 2nd Author & \\
\hline 3 & Vaqar-e-Sahar Shah & 3rd Author & \\
\hline 4 & Saima Ather Shaikh & 4th Author & Samis \\
\hline 5 & Shabnum Naz Shaikh & 5th Author & Shatruerm - \\
\hline 6 & Ehsanullah Malik & 6th Author & \\
\hline
\end{tabular}

